\title{
MADUREZ SINTÁCTICA EN NIÑOS PREESCOLARES COSTARRICENSES
}

\author{
Víctor Ml. Sánchez Corrales
}

\begin{abstract}
RESUMEN
En el presente trabajo se estudia la madurez sintáctica de niños preescolares vallecentraleños, respecto del número de palabras del enunciado conocido como unidad T, cantidad de cláusulas que lo integran y número de vocablos de éstas, con el propósito de describir cuantitativamente el desarrollo sintáctico de treinta niños preescolares del Valle Intermontano Central. Este trabajo se enmarca, en términos generales, en la línea de investigación de Kellog W. Hunt $(1965,1967,1970)$ y en los estudios de De Olloqui de Montenegro (1991), Rodríguez Fonseca (1991), Vázquez (1991) y Herrera Lima (1991).
\end{abstract}

\begin{abstract}
This article presents a quantitative description of the syntactic maturity of thirty preschoolers from the Central Valley, in relation to the number of words in the unit referred to as $\mathrm{T}$ and including its total number of clauses and number of words per clause. In general terms, this work follows the research guidelines defined by Kellog W. Hunt (1965, 1967, 1970) and the works by De Olloqui de Montenegro (1991), Rodríguez Fonseca (1991), Vázquez (1991) and Herrera Lima (1991).
\end{abstract}

\section{Introducción}

El concepto de lengua española que predomina en el sistema educativo costarricense se fundamenta en la doctrina gramatical de la Real Academia Española. La gramática, en su condición de arte, requiere la enseñanza-aprendizaje de ciertos principios idiomáticos que se abstraen del uso lingüístico culto y, en particular, del discurso literario, para "hablar o escribir bien". Esta práctica pedagógica favorece la adquisición de un metalenguaje, depara, en el mejor de los casos, un conocimiento parcial de la lengua española en su condición de lengua histórica y privilegia una variedad respecto de las otras variedades del diasistema español, al erigirla como la lengua por excelencia.

En un estudio de 1989, el autor señaló la imperiosa necesidad de cambiar ese modelo de lengua, con las correspondientes consecuencias en la planificación lingüística.

El paso del modelo "académico" al sociolingüístico, la sustitución del concepto de 'corrección idiomática' por el de 'adecuación comunicativa' implican un cambio de saberes, 
de objetivos y de prácticas pedagógicas: estudiar cosas sobre la lengua en vez de la lengua, prioridad de la producción y decodificación del discurso respecto del conocimiento del metalenguaje, y política lingüística y elaboración de materiales didácticos, fundamentadas en la competencia comunicativa de los sujetos de la educación y no solo a partir de la lengua literaria de ayer y de hoy.

En la presente comunicación quisiera insistir en la necesidad de una labor conjunta de lingüistas y pedagogos, para contribuir a una adecuada planificación lingüística en lo relativo a la enseñanza-aprendizaje del español como lengua materna en el sistema educativo costarricense.

La educación debe proporcionar al educando la variedad de español que le permita la interacción verbal exitosa como garantía del progreso académico social y económico. El uso adecuado de un registro más rico, más variado, más preciso, vehículo de cultura, concebido e identificado desde el diasistema español, promueve el ascenso social del hablante a los estratos más altos de la sociedad. En este sentido, la enseñanża-aprendizaje del español como lengua nacional, debe fundamentarse en un adecuado programa de investigaciones lingüísticas sobre variedades del español en Costa Rica habladas por los educandos de los distintos niveles de nuestro sistema educativo e igualmente sobre el uso lingüístico culto costarricense, en su condición de variedad meta o lengua ideal del proceso enseñanza-aprendizaje.

En la ponencia plenaria "Aportes de la lingǘstica a la enseñanza del español como lengua materna: competencia sintáctica en niños preescolares", leída en el "II Simposio de Educación Preescolar: estado actual y perspectivas de la educación preescolar en Costa Rica", Ciudad Universitaria Rodrigo Facio, 10-14 de febrero de 1995 y por aparecer en la Revista Educación, Vol. 19, № 1, el autor presenta una visión de conjunto sobre el estado de la cuestión relativo a la investigación de la norma lingüística culta costarricense y a los estudios sobre la competencia lingüística de los educandos, habiendo llegado a la conclusión de que las investigaciones de lingüística aplicada al español de Costa Rica como lengua materna, en aras de contribuir a la enseñanza-aprendizaje, están en una etapa inicial y han versado solo sobre dos componentes: el léxico y el fonológico. De ahí la conveniencia de reforzar esta línea de investigación y explorar un campo como el de la sintaxis.

\section{Madurez sintáctica en niños preescolares costarricenses}

\subsection{Aspectos generales}

En el presente trabajo se estudia, a manera de cala, la madurez sintáctica de niños preescolares vallecentraleños, respecto del número de palabras del enunciado conocido como unidad T, cantidad de cláusulas que lo integran y número de vocablos de éstas.

Para una adecuada planificación lingüística, elaboración de planes de estudio y de materiales didácticos, organización de actividades, es fundamental que la maestra de educación preescolar conozca el desarrollo sintáctico del niño, además de su competencia lingüística en los otros niveles de la lengua.

Este trabajo se enmarca, en términos generales, en la línea de investigación de Kellog W. Hunt $(1965,1967,1970)$ y en los estudios de De Olloqui de Montenegro (1991), Rodríguez Fonseca (1991), Vázquez (1991) y Herrera Lima (1991). Nos proponemos describir cuantitativamente el desarrollo sintáctico de treinta niños preescolares del Valle Intermontano Central. 


\subsection{Principios teóricos}

Hay varios procedimientos -cuantitativos unos, cualitativos otros- para medir el grado de complejidad sintáctica de una oración y con ello la madurez alcanzada en el componente sintáctico por el respectivo hablante.

Hunt define la madurez sintáctica como la habilidad de producir oraciones de mayor complejidad estructural y comprueba que dicha habilidad está en relación directa con la edad, pues cuanto mayor sea el niño, más complejos serán los enunciados que emita; este investigador propone tres índices básicos, estrechamente relacionados, para medir la madurez sintáctica de los niños en la producción escrita: longitud promedio de la unidad $\mathrm{T}$, longitud promedio de la cláusula y promedio de cláusulas por unidad T o índice de subordinación.

Detengámonos brevemente en cada principio.

La unidad T o unidad mínima terminal corresponde a lo que en la gramática tradicional del español se denomina oración simple u oración compuesta por subordinación. Son ejemplos de unidad T: I le pegaron a Marcos \$ y \$ cuando dejó la refri vacía llegó a ver si había algo para hacer una sopa $\$$ ] cuyo inicio y término hemos marcado con el signo de dólares. Es evidente que el segundo ejemplo es gramaticalmente más complejo. Hunt la define como "la unidad más corta en que puede dividirse una pieza de discurso sin dejar ningún fragmento de oración como residuo" y cada una de esas unidades constan de una cláusula principal más cualquier cláusula o cláusulas subordinadas a ella.

La cláusula se define como una construcción sintácticamente libre o subordinada, articulada en sujeto y predicado, con el verbo en forma personal. Corresponde a lo que en la gramática tradicional del español se denomina oración simple, oración subordinante y oración subordinada, ya sea bimembre, impersonal o unipersonal. Son ejemplos de cláusulas [\% hormiguita, ¿me puedo casar contigo \% (oración simple) y \% había una vez una chiquita \% (oración subordinante impersonal), \% que se llamaba Capelucita \% (oración subordinada bimembre)], cuyo inicio y cierre hemos marcado con el signo de porcentaje.

Finalmente el índice de subordinación expresa el número promedio de cláusulas - principales y subordinadas - por unidad T. En el siguiente texto: [ \$ \% había una vez una chiquita \% $\%$ que se llamaba nancanieves $\%$ y $\$ \%$ tenía una mamá $\% \%$ que era una bruja $\% \$$ (intonces) $\$ \%$ mandó a un neyador \% \% que matara a (un a) nancanieves \% (y) \% le sacara el corazón \%\$ (y) \$\% mató a un venao \% \$ (y) \$\% le llevó el corazón del venao \% \$], tenemos cinco unidades $\mathrm{T}$ y nueve cláusulas, lo que da un promedio de 1,8 cláusulas por unidad $\mathrm{T}$. En ese texto, en consecuencia, el índice de subordinación o frecuencia de cláusulas por unidad T es de 1,8.

\subsection{La muestra y el corpus}

La muestra está constituida por 30 niños preescolares procedentes de centros educativos públicos marginales, públicos urbanos y privados, distribuidos equitativamente y cuya selección se hizo por conveniencia. La distribución por sexo corresponde a 13 niños y 17 niñas y por tipo de institución a la que asisten los niños: urbano, marginal (ambos públicos) y privado, 10 en cada caso. Los centros educativos están ubicados en diferentes puntos del Valle Intermontano Central. 
La recolección del corpus se hizo mediante conversación dirigida, con el fin de obtener discursos narrativos, habiendo sido recogidos, grabados y transcritos por las estudiantes del curso FO 3103 Artes del Lenguaje I para Preescolar, segundo ciclo de 1994, bajo la guía de la profesora Marielos Murillo Rojas. El corpus consta de 43 textos narrativos, correspondientes a los 30 informantes.

\subsection{Segmentación de los textos}

Como el material recogido corresponde al código oral, producido en una interacción comunicativa cara a cara, se hizo necesario eliminar los enunciados fragmentarios, no oracionales, pues tienen relevancia solo en la interacción; igualmente se obviaron enunciados agramaticales, falsos comienzos, vacilaciones como consecuencia de distracciones o lapsus de memoria del hablante. También se prescindió de los nexos pragmáticos del tipo bueno, diay, verdad, entonces; tampoco se contabilizaron las conjunciones coordinantes y, pero. Las perífrasis paradigmáticas de haber + participio como tiempos compuestos se contaron como una sola palabra.

Realizada la poda anterior se procedió a segmentar y codificar el corpus en unidades T y en cláusulas, para procesar esos textos en un programa cuantificador de estructuras sintácticas, cuya elaboración correspondió al señor Franklin Ureña Camacho, funcionario del Centro de Informática de la Universidad de Costa Rica.

Los datos preliminares obtenidos fueron correlacionados con las variables sociolingüísticas, tipo de institución y sexo, al aplicárseles el programa estadístico SAS.

\subsection{Análisis de los datos}

La aplicación del programa cuantificador de estructuras sintácticas a los 43 textos de los 30 informantes, produjo los siguientes datos:

Lista 1

Madurez sintáctica de niños preescolares

Ordenamiento por informante

Total unidades T (TOT-UNI)

Total cláusulas (TOT-C)

Total palabras (TOT-PAL)

$\begin{array}{cllccc}\text { INFOR } & \text { GRUPO } & \text { SEXO } & \text { TOT_UNI } & \text { TOT_C } & \text { TOT_PAL } \\ 1 & \text { Privado } & \text { Mujer } & 21 & 34 & 145 \\ 2 & \text { Marginal } & \text { Mujer } & 39 & 80 & 240 \\ 3 & \text { Privado } & \text { Mujer } & 56 & 143 & 425 \\ 4 & \text { Marginal } & \text { Mujer } & 15 & 28 & 111 \\ 5 & \text { Marginal } & \text { Hombre } & 8 & 10 & 69 \\ 6 & \text { Marginal } & \text { Mujer } & 21 & 34 & 124 \\ 7 & \text { Marginal } & \text { Mujer } & 10 & 12 & 53 \\ 8 & \text { Urbano } & \text { Mujer } & 5 & 5 & 29 \\ 9 & \text { Privado } & \text { Hombre } & 33 & 67 & 208\end{array}$




$\begin{array}{llllll}10 & \text { Urbano } & \text { Hombre } & 15 & 35 & 120 \\ 11 & \text { Marginal } & \text { Mujer } & 23 & 30 & 142 \\ 12 & \text { Urbano } & \text { Hombre } & 21 & 34 & 95 \\ 13 & \text { Urbano } & \text { Hombre } & 42 & 113 & 238 \\ 14 & \text { Urbano } & \text { Hombre } & 35 & 81 & 324 \\ 15 & \text { Privado } & \text { Mujer } & 31 & 50 & 194 \\ 16 & \text { Urbano } & \text { Hombre } & 10 & 12 & 50 \\ 17 & \text { Privado } & \text { Mujer } & 24 & 30 & 133 \\ 18 & \text { Urbano } & \text { Mujer } & 28 & 52 & 184 \\ 19 & \text { Urbano } & \text { Mujer } & 16 & 20 & 79 \\ 20 & \text { Marginal } & \text { Hombre } & 45 & 66 & 241 \\ 21 & \text { Privado } & \text { Hombre } & 26 & 38 & 162 \\ 22 & \text { Privado } & \text { Mujer } & 22 & 45 & 157 \\ 23 & \text { Marginal } & \text { Mujer } & 14 & 34 & 92 \\ 24 & \text { Marginal } & \text { Mujer } & 19 & 40 & 100 \\ 25 & \text { Privado } & \text { Mujer } & 21 & 40 & 126 \\ 26 & \text { Marginal } & \text { Mujer } & 41 & 62 & 242 \\ 27 & \text { Urbano } & \text { Hombre } & 3 & 3 & 15 \\ 28 & \text { Privado } & \text { Hombre } & 22 & 35 & 137 \\ 29 & \text { Marginal } & \text { Hombre } & 3 & 3 & 24 \\ 30 & \text { Privado } & \text { Hombre } & 7 & 9 & 41 \\ & & & & & 4300 \\ & & \text { TOTAL } & 676 & 1245 & 143,33 \text { ) }\end{array}$

Lista 2

$\begin{array}{llllll}\text { INFOR } & \text { GRUPO } & \text { SEXO } & \text { LP_UT } & \text { LP_CL } & \text { IND_SUB } \\ 1 & \text { Privado } & \text { Mujer } & 6,90 & 4,26 & 1,62 \\ 2 & \text { Marginal } & \text { Mujer } & 6,15 & 3,00 & 2,05 \\ 3 & \text { Privado } & \text { Mujer } & 7,59 & 2,97 & 2,55 \\ 4 & \text { Marginal } & \text { Mujer } & 7,40 & 3,96 & 1,87 \\ 5 & \text { Marginal } & \text { Hombre } & 8,63 & 6,90 & 1,25 \\ 6 & \text { Marginal } & \text { Mujer } & 5,90 & 3,65 & 1,62 \\ 7 & \text { Marginal } & \text { Mujer } & 5,30 & 4,42 & 1,20 \\ 8 & \text { Urbano } & \text { Mujer } & 5,80 & 5,80 & 1,00 \\ 9 & \text { Privado } & \text { Hombre } & 6,30 & 3,10 & 2,03 \\ 10 & \text { Urbano } & \text { Hombre } & 8,00 & 3,43 & 2,33 \\ 11 & \text { Marginal } & \text { Mujer } & 6,17 & 4,73 & 1,30 \\ 12 & \text { Urbano } & \text { Hombre } & 4,52 & 2,79 & 1,62 \\ 13 & \text { Urbano } & \text { Hombre } & 5,67 & 2,11 & 2,69 \\ 14 & \text { Urbano } & \text { Hombre } & 9,26 & 4,00 & 2,31 \\ 15 & \text { Privado } & \text { Mujer } & 6,26 & 3,88 & 1,61 \\ 16 & \text { Urbano } & \text { Hombre } & 5,00 & 4,17 & 1,20 \\ 17 & \text { Privado } & \text { Mujer } & 5,54 & 4,43 & 1,25 \\ 18 & \text { Urbano } & \text { Mujer } & 6,57 & 3,54 & 1,86 \\ 19 & \text { Urbano } & \text { Mujer } & 4,94 & 3,95 & 1,25 \\ 20 & \text { Marginal } & \text { Hombre } & 5,36 & 3,65 & 1,47 \\ 21 & \text { Privado } & \text { Hombre } & 6,23 & 4,26 & 1,46 \\ 22 & \text { Privado } & \text { Mujer } & 7,14 & 3,49 & 2,05 \\ 23 & \text { Urbano } & \text { Mujer } & 6,57 & 2,71 & 2,43 \\ 24 & \text { Marginal } & \text { Mujer } & 5,26 & 2,50 & 2,11\end{array}$




$\begin{array}{llllll}25 & \text { Privado } & \text { Mujer } & 6,00 & 3,15 & 1,90 \\ 26 & \text { Marginal } & \text { Mujer } & 5,90 & 3,90 & 1,51 \\ 27 & \text { Urbano } & \text { Hombre } & 5,00 & 5,00 & 1,00 \\ 28 & \text { Privado } & \text { Hombre } & 6,23 & 3,91 & 1,59 \\ 29 & \text { Marginal } & \text { Hombre } & 8,00 & 8,00 & 1,00 \\ 30 & \text { Privado } & \text { Hombre } & 5,86 & 4,56 & 1,29 \\ & & & & & \\ & & & & & \\ & & & 6,0,315 & & 1,68)\end{array}$

Al correlacionar la variable sexo con la longitud promedio de la unidad $\mathrm{T}$, la longitud promedio de la cláusula y con el índice de subordinación, tenemos los siguientes datos:

\section{Cuadro 1}

$\begin{array}{ccccccc}\text { Sexo } & \text { PR-U } & \text { PR_C } & \text { PR_PAL } & \text { LP_UT } & \text { LP_C } & \text { IND_SUB } \\ \text { Mujer } & 23,88 & 43,47 & 151,53 & 6,34 & 3,49 & 1,82 \\ \text { Hombre } & 20,77 & 38,92 & 132,61 & 6,39 & 3,41 & 1,87\end{array}$

Podemos observar que los hombres superan levemente a las mujeres en el número promedio de palabras por enunciado, es decir la longitud promedio de la unidad $\mathrm{T}$ tiene 6,39 palabras, mientras que en las mujeres presenta 6,34 , lo que equivale a una diferencia de 0,05 . Una situación semejante encontramos en el índice de subordinación, ya que las mujeres tienen 1,82 y los hombres 1,87. Estas diferencias no son significativas a un nivel de significancia de 0,05. Por su parte, las mujeres superan levemente a los hombres en el número promedio de palabras por cláusula, ya que la longitud promedio por cláusula es de 3,49 frente a 3,41 de los hombres. Esta diferencia tampoco resulta significativa a un nivel de significancia de 0,05.

Respecto de la variable tipo de institución: privado, público urbano y público marginal, correlacionada con la longitud promedio de la unidad $\mathrm{T}$, longitud promedio de la cláusula e índice de subordinación, se obtienen los siguientes datos:

\section{Cuadro 2}

$\begin{array}{lllllll}\text { Grupo } & \text { PR_U } & \text { PR_C } & \text { PR_PAL } & \text { LP_UT } & \text { LP_C } & \text { IND_SUB } \\ \text { Urbano } & 18,9 & 38,9 & 122,6 & 6,49 & 3,15 & 2,06 \\ \text { Marginal } & 22,4 & 36,5 & 134,6 & 6,01 & 3,69 & 1,63 \\ \text { Privado } & 26,3 & 49,1 & 172,8 & 6,57 & 3,52 & 1,87\end{array}$


Se puede notar que los niños vallecentraleños de instituciones marginales presentan los porcentajes más bajos en cuanto al número promedio de palabras por enunciado: 6,01 frente a 6,49 y 6,51 del grupo urbano y privado respectivamente. Una situación análoga se repite en cuanto al índice de subordinación: 1,63 frente a 2,06 y 1,87 de los grupos urbano y privado respectivamente. Al presentarse un índice de subordinación más bajo en el grupo marginal, la longitud promedio de la cláusula es levemente más larga: 3,69 frente a 3,15 y 3,52 de los grupos urbano y privado respectivamente. Estos datos nos permiten concluir que el grupo marginal es sintácticamente más inmaduro que los grupos urbano y privado, pero que esa diferencia cuantitativa en la longitud promedio de la unidad $\mathrm{T}$ y en el índice de subordinación, no resulta significtiva a un nivel de significancia de 0,05 .

Por otra parte, al categorizar los grupos urbano y marginal como público frente al grupo privado, tenemos lo siguiente:

\section{Cuadro 3}

$\begin{array}{llllllc}\text { Grupo } & \text { PR_U } & \text { PR_C } & \text { PR_PAL } & \text { LP_UT } & \text { LP_C } & \text { IND_SUB } \\ \text { Privado } & 26,30 & 49,1 & 172,8 & 6,57 & 3,52 & 1,87 \\ \text { Público } & 20,65 & 37,7 & 128,6 & 6,23 & 3,41 & 1,83\end{array}$

Al comparar los datos de las columnas longitud promedio de la unidad T, longitud promedio de la cláusula e índice de subordinación, notamos que los niños vallecentraleños de instituciones privadas presentan 6,57 (LP_T), 3,52 (LP_C) y 1,87 (IND_SUB), frente a 6,23, 3,41 y 1,83 respectivamente de los niños que asisten a instituciones públicas. Como consecuencia esos niños de instituciones privadas tienen una leve superioridad en la madurez sintáctica, a pesar de que la diferencia no es significativa a un nivel de significancia del 0,05.

Si bien las variables sexo y tipo de institución a la que asisten los niños no presentan diferencias significativas, sí se puede concluir que los factores sociales -marginal, urbano/ privado, público/privado- marcan más las diferencias de madurez sintáctica en la población estudiada.

\section{A manera de conclusión}

Estos estudios cuantitativos deben complementarse con investigaciones cualitativas para determinar cuáles son las estructuras sintácticas incorporadas en la competencia comunicativa del niño y cuáles son las ausentes, con el fin de que la planificación lingüística, el currículum, la elaboración de materiales y las actividades, se fundamenten en un conocimiento objetivo de la competencia comunicativa de los sujetos de la educación, además de la variante culta como lengua meta. Y es en este estadio de la investigación en el que el trabajo interdisciplinario de lingüistas y pedagogos se hace impostergable e imprescindible. 


\section{Bibliografía}

De Olloqui de Montenegro, L. 1991. "La investigación de la madurez sintáctica y la enseñanza de la lengua materna". En: López Morales (ed.), 111-131.

Herrera Lima, M.E. 1991. "Madurez sintáctica en escolares de la ciudad de México. Análisis preliminar”. En: López Morales (ed.), 155-169.

Hernández, C. et al (eds.). 1989/1991. El Español de América 3. Salamanca: Gráficas Verona.

Hunt, W. K. 1970a. "Recent measures in syntactic development”. En: Lester (ed.), 179-192.

1970b. "How little sentences grow into big ones". En: Lester (ed.), 193-201.

1970c. "Syntactic maturity in schoolchildren and adults". Monographs of the Society of Research in Child Development. Serial No 134. 35 (3).

Lester, Mark (ed.). 1970. Readings in applied transformation grammar. New York: Holt, Rinehart and Winston.

López Morales, Humberto. 1986/1990. Enseñanza de la lengua materna. Madrid: Editorial Plaza Mayor, Inc.

(ed.) 1991. La enseñanza del español como lengua materna. Río Piedras: Editorial de la Universidad de Puerto Rico.

Rodríguez Fonseca, L. 1991. "Índices de madurez sintáctica en escolares puertorriqueños de escuela primaria”. En: López Morales (ed.), 133-143.

Sánchez Corrales, Víctor. 1989/1991. "La lengua española en la educación costarricense, redefinición”. En: Hernández et al. (eds.), 1211-1218.

1993. "La enseñanza del español en la educación preescolar costarricense". Educación. 17 (1): 109-116.

"Aportes de la lingüística a la enseñanza del español como lengua materna en Costa Rica: competencia sintáctica en niños preescolares”, por aparecer en Revista Educación de la Universidad de Costa Rica, 19 ( 1).

Vázquez, I. 1991. "Índices de madurez sintáctica en estudiantes puertorriqueños de escuela superior”. En: López Morales (ed.), 146-153. 